\title{
Effects of Particulate Matter 10 Inhalation on Lung Tissue RNA expression in a Murine Model
}

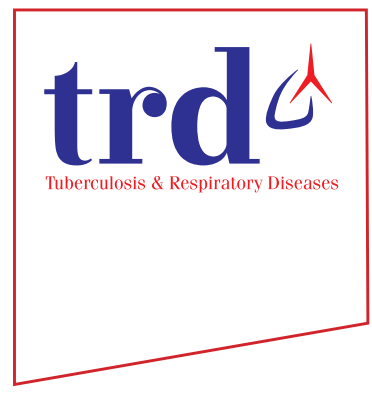

\author{
Heejae Han, M.S. ${ }^{1}{ }^{(\mathbb{D}}$, Eun-Yi Oh, M.S. ${ }^{2}$, Jae-Hyun Lee, M.S. ${ }^{2,3}$, Jung-Won Park, M.S. ${ }^{2,3}$ and Hye Jung \\ Park, M.D., Ph.D. ${ }^{1}$ (i) \\ ${ }^{1}$ Department of Internal Medicine, Gangnam Severance Hospital, Seoul, ${ }^{2}$ Institute of Allergy, Yonsei University College \\ of Medicine, Seoul, ${ }^{3}$ Division of Allergy and Immunology, Department of Internal Medicine, Yonsei University College of \\ Medicine, Seoul, Republic of Korea
}

Background: Particulate matter $10\left(\mathrm{PM}_{10}\right.$; airborne particles $\left.<10 \mu \mathrm{m}\right)$ inhalation has been demonstrated to induce airway and lung diseases. In this study, we investigate the effects of $\mathrm{PM}_{10}$ inhalation on RNA expression in lung tissues using a murine model.

Methods: Female BALB/c mice were affected with $\mathrm{PM}_{10}$, ovalbumin (OVA), or both OVA and $\mathrm{PM}_{10}$. $\mathrm{PM}_{10}$ was administered intranasally while OVA was both intraperitoneally injected and intranasally administered. Treatments occurred 4 times over a 2-week period. Two days after the final challenges, mice were sacrificed. Full RNA sequencing using lung homogenates was conducted.

Results: While $\mathrm{PM}_{10}$ did not induce cell proliferation in bronchoalveolar fluid or lead to airway hyper-responsiveness, it did cause airway inflammation and lung fibrosis. Levels of interleukin $1 \beta$, tumor necrosis factor- $\alpha$, and transforming growth factor- $\beta$ in lung homogenates were significantly elevated in the $\mathrm{PM}_{10}$-treated group, compared to the control group. The $\mathrm{PM}_{10}$ group also showed increased RNA expression of Rn45a, Snord22, Atp6v0c-ps2, Snora28, Snord15b, Snora70, and Mmp12. Generally, genes associated with RNA splicing, DNA repair, the inflammatory response, the immune response, cell death, and apoptotic processes were highly expressed in the $\mathrm{PM}_{10}$-treated group. The OVA/PM 10 treatment did not produce greater effects than OVA alone. However, the OVA/ $\mathrm{PM}_{10}$-treated group did show increased RNA expression of Clca1, Snord22, Retnla, Prg2, Tff2, Atp6v0c-ps2, and Fcgbp when compared to the control groups. These genes are associated with RNA splicing, DNA repair, the inflammatory response, and the immune response. Conclusion: Inhalation of $\mathrm{PM}_{10}$ extensively altered RNA expression while also inducing cellular inflammation, fibrosis, and increased inflammatory cytokines in this murine mouse model.

Keywords: Particulate Matter; RNA Sequencing; Lung

Address for correspondence: Hye Jung Park, M.D., Ph.D.

Division of Pulmonology, Department of Internal Medicine, Gangnam Severance Hospital, Yonsei University College of Medicine, 211 Eonju-ro,

Gangnam-gu, Seoul 06273, Republic of Korea

Phone: 82-2-2019-3302, Fax: 82-2-3463-3882, E-mail: craft7820@yuhs.ac

Received: Sep. 15, 2020, Revised: Oct. 21, 2020, Accepted: Nov. 30, 2020, Published online: Nov. 30, 2020

@(t) is identical to the Creative Commons Attribution Non-Commercial License (http://creativecommons.org/licenses/by-nc/4.0/). 


\section{Introduction}

Air pollution is an important problem worldwide, and it certainly has negative effects on general health ${ }^{1-3}$. Particulate matter $10\left(<10 \mu \mathrm{m} ; \mathrm{PM}_{10}\right)$ is a one of the major components of air pollution. It includes high levels of elements such as silicon, barium, aluminum, zinc, copper, and lead ${ }^{4,5} . \mathrm{PM}_{10}$ enters the airway through the nose and mouth, and as a result it can potentially cause injury to the respiratory tract, including the trachea, bronchus, alveoli, and even lung parenchyma. Studies have also indicated that chronic and intensive inhalation of $\mathrm{PM}_{10}$ can induce and enhance airway and lung diseases. For example, epidemiologic data have shown that asthma can be developed and aggravated by ambient pollutants like $\mathrm{PM}_{10}{ }^{6-8}$, and chronic obstructive pulmonary disease (COPD) is also sensitive to $\mathrm{PM}_{10}$ exposure $^{9-12}$.

Some indications of the mechanisms underlying these effects have been found ${ }^{13}$. For example, innate and adaptive immune responses in the airway and lung can be altered by extrinsic irritants in general ${ }^{14}$, and $\mathrm{PM}_{10}$ exposure can alter mechanical and immunological barriers in airway disease ${ }^{15}$. At the molecular level, evidence indicates that interleukin (IL)-1 $\beta$, IL-6, NOD-like receptor pyrin domain-containning protein 3 , and chemokine (C-C motif) ligand 20 may be key
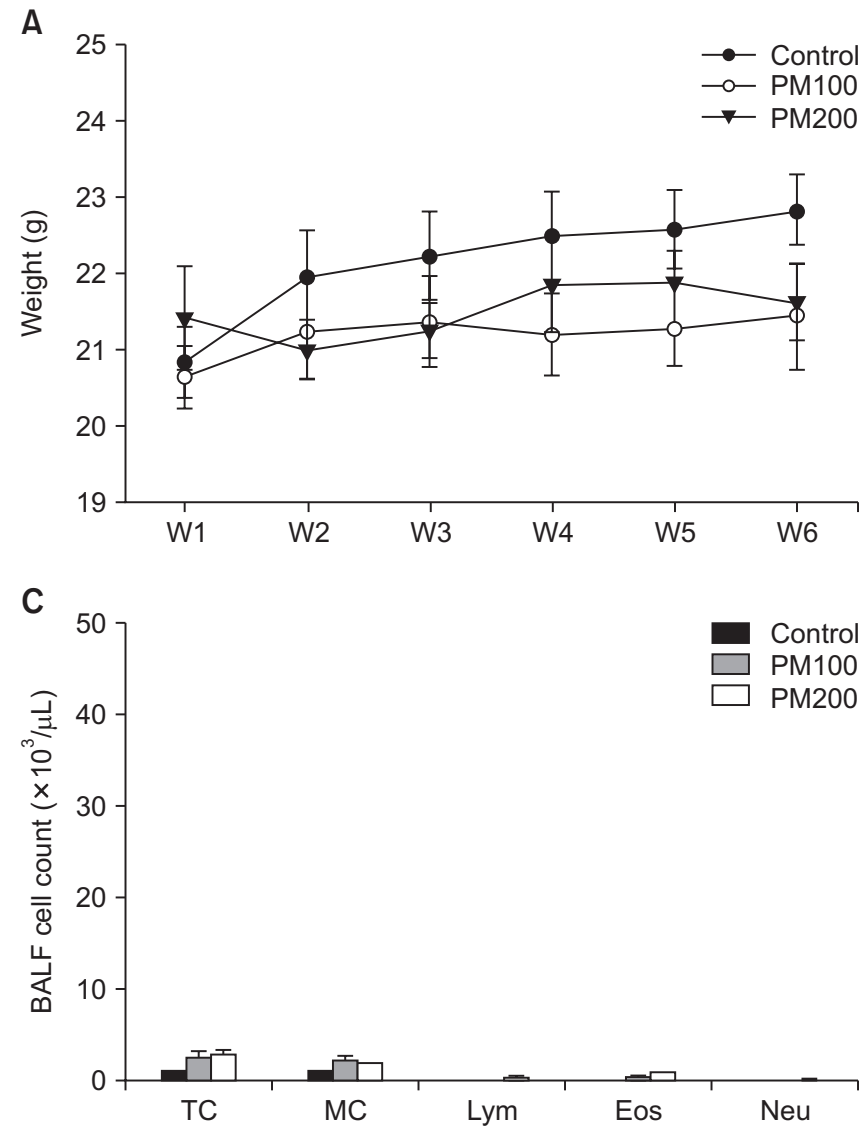

mediators of the effects of $\mathrm{PM}_{10}$ on airway and lung tissue ${ }^{16-18}$. However, $\mathrm{PM}_{10}$ particles are extremely small and consist of variable elements. We therefore hypothesized that $\mathrm{PM}_{10}$ can alter RNA expression in extensive range, potentially leading to visible inflammation and other side effects. Elucidating the patterns of RNA expression changes in response to $\mathrm{PM}_{10}$ in a murine model may be helpful for predicting its effects on human health.

\section{Materials and Methods}

\section{Animal model designs}

Female BALB/c mice, between 5 and 6 weeks old (Orient, Daejeon, Korea), were maintained at conventional animal facilities under pathogen-free conditions, and five mice were assigned in each group. To establish the $\mathrm{PM}_{10}$-induced murine model $\left(\mathrm{PM}_{10}\right.$ model), $\mathrm{PM}_{10}$ (ERMCZ-120 certified reference material; Sigma-Aldrich, St. Louis, MO, USA; $100 \mu \mathrm{g}$ [PM100] or $200 \mu \mathrm{g}$ [PM200]) suspended in $20 \mu \mathrm{L}$ normal saline was intranasally administered four times over 2 weeks. To establish the ovalbumin (OVA)-induced asthma murine model (OVA model), mice were sensitized with $20 \mu \mathrm{g}$ OVA (Sigma-Aldrich)

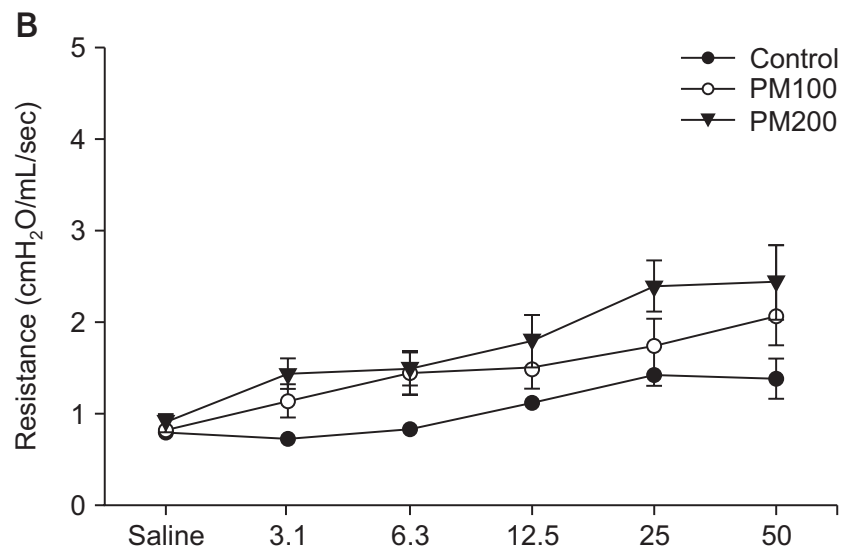

Figure 1. (A) Weight change did not significantly differ among groups. (B) Airway hyper-responsiveness as determined by methacholine challenge showed no significant difference among groups. (C) There were no significant differences in the BALF cell counts between groups. BALF: bronchoalveolar lavage fluid; PM: particulate matter; TC: total cell; MC: macrophage; Lym: lymphocyte; Eos: eosinophil; Neu: neutrophil. 
suspended in 1\% aluminum hydroxide (Resorptar; Indergen, New York, NY, USA) by intraperitoneal injection on days 1 and 14 . On days 21,22 , and 23, the OVA-sensitized mice were challenged intranasally with $30 \mu \mathrm{L}$ of OVA $(1 \mathrm{mg} / \mathrm{mL})$ in saline solution. An OVA/ $\mathrm{PM}_{10}$-treated model was established by the above two treatments simultaneously. All mice were sacrificed 2 days after their last treatment (Supplementary Figure S1). All experimental procedures of mice studies were approved by the Institutional Animal Care and Use Committee, Animal Research Ethics Board of Yonsei University (Seoul, Korea) (IACUC approval number, 2020-0087) and were performed in accordance with the Committee's guidelines and regulations for animal care.

\section{Measurement of airway hyper-responsiveness}

Airway hyper-responsiveness (AHR) to inhaled aerosolized methacholine (MCh; Sigma-Aldrich) was measured using a forced oscillation technique (FlexiVent; SCIREQ, Montreal, QC, Canada) on the sacrifice day, as described in a previous study ${ }^{19-21}$. Aerosolized phosphate-buffered saline or MCh at varying concentrations $(3.125 \mathrm{mg} / \mathrm{mL}, 6.25 \mathrm{mg} / \mathrm{mL}, 12.5 \mathrm{mg} /$ $\mathrm{mL}, 25.0 \mathrm{mg} / \mathrm{mL}$, or $50.0 \mathrm{mg} / \mathrm{mL}$ ), was administered to mice for $10 \mathrm{~s}$ via a nebulizer connected to a ventilator. Then, AHR was assessed by measurements of airway resistance.

\section{Inflammatory cell counting in bronchoalveolar lavage fluid}

To collect bronchoalveolar lavage fluid (BALF), we per- formed lung lavage, using $1 \mathrm{~mL}$ of Hank's balanced salt solution (HBSS) through a tracheal tube. The recovered BALF was centrifuged and resuspended in $300 \mu \mathrm{L}$ HBSS. Total cell numbers were determined using a hemocytometer and trypan blue staining. BALF cells were centrifuged by cytocentrifugation (Cytospin 3; Thermo Fisher Scientific, Waltham, MA, USA) and were pelleted to cytospin slides. The slides were stained with hematoxylin and eosin (H\&E Hemacolor; Merck, Darmstadt, Germany) and a differential count of inflammatory cells was performed ( 200 cells per slide).

\section{Histological analysis}

The lung that was not used for BALF collection was fixed in $4 \%$ formalin and embedded in paraffin. Lung sections were cut into 3-4- $\mu \mathrm{m}$-thick slices and stained with $\mathrm{H} \& \mathrm{E}$, periodic acid-Schiff, and Masson trichrome (M\&T) for histological analysis. The slides were observed under a light microscope $(\times 200$ magnification). Fibrosis area was measured by estimating the color-pixel count over the pre-set threshold color on M\&T-stained slides at $\times 200$ magnification using MetaMorph program (Molecular Devices, Sunnyvale, CA, USA).

\section{Lung homogenate}

After collecting BALF, remaining lung tissue was resected and homogenized using a tissue homogenizer (Biospec Products, Bartlesville, OK, USA) in lysis buffer and protease inhibitor solution (Sigma-Aldrich). After incubation and centrifugation, supernatants were harvested and passed through a

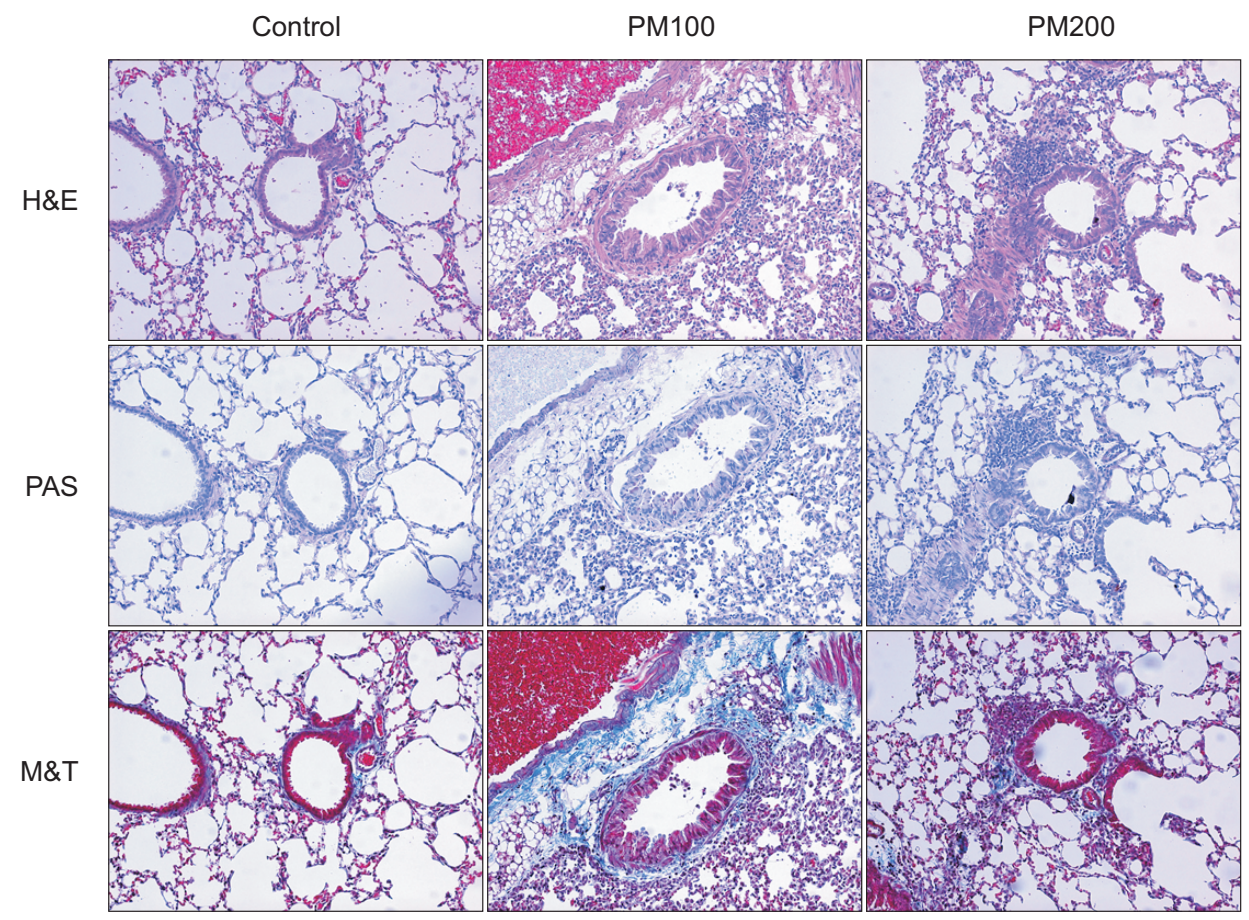

Figure 2. Pathological analysis revealed $\mathrm{PM}_{10}$ treatment led to airway inflammation and lung fibrosis (H\&E, PAS, and M\&T; $\times 200)$. H\&E: hematoxylin and eosin; PAS: periodic acid-Schiff; PM: particulate matter; M\&T: Masson trichrome. 
0.45-micron filter (Gelman Science, Ann Arbor, MI, USA). The final preparations were stored at $-20^{\circ} \mathrm{C}$ for cytokine analysis as described previously ${ }^{19}$.

\section{Analysis of cytokines}

Concentrations of interleukin (IL)- $1 \beta$, tumor necrosis factor- $\alpha$ (TNF- $\alpha)$, IL-13, and transforming growth factor- $\beta$ (TGF- $\beta$ ) in lung homogenates were assessed by enzymelinked immunosorbent assay (R\&D Systems, San Diego, CA, USA) according to the manufacturer's instructions. All samples were assessed in duplicate.

\section{Full RNA sequencing}

Total RNA was extracted from lung tissue using Trizol reagent (Invitrogen, Carlsbad, CA, USA). The isolated mRNAs were used for cDNA synthesis. Libraries were prepared using the NEBNext Ultra II Directional RNA Seq Kit (New England BioLabs, Inc., Hitchin, UK). Indexing was performed using the Illumina indexes 1-12. The enrichment step was carried out using polymerase chain reaction (PCR). Subsequently, libraries were checked using the Agilent 2100 bioanalyzer (Agilent Technologies, Amstelveen, The Netherlands), to evaluate the mean fragment size. Quantification was performed using the library quantification kit with an ND 2000 Spectrophotometer (Thermo Fisher Scientific) and StepOne Real Time PCR System (Life Technologies, Inc., Carlsbad, CA, USA). Highthroughput sequencing was performed as paired end $100 \mathrm{se}-$ quencing using NovaSeq 6000 (Illumina, Inc., San Diego, CA, USA).

Quality control of raw sequencing data was performed using FastQC (Simon, 2010). The results of fast QC are presented in Supplementary Figure S2. Adapter and low-quality reads $(<\mathrm{Q} 20)$ were removed using FASTX_Trimmer (Hannon
Lab, 2014) and BBMap (Bushnell, 2014). Then, the trimmed reads were mapped to the reference genome using TopHat ${ }^{22}$. Gene expression levels were estimated by calculating fragments per kb per million reads (FPKM) using Cufflinks ${ }^{23}$. The FPKM values were normalized based on a quantile normalization method using EdgeR within R (R development Core Team, 2016). Data mining and graphic visualization including define upregulated or downregulated gene expression were performed using ExDEGA (E-Biogen, Inc., Seoul, Korea).

\section{Statistical analysis}

All results are expressed as the mean \pm standard error. The AHR data were analyzed using repeated-measure analysis of variance (ANOVA), followed by a post-hoc Bonferroni test. One-way ANOVA was performed to assess the significance of differences in BALF cell count, cytokine levels, and quantitative fibrosis among groups. All statistical analyses were performed with IBM SPSS version 18.0 (SPSS Inc., Chicago, IL, USA). p-values $<0.05$ were considered statistically significant.

\section{Results}

\section{Comparison of weight changes, AHR, and BALF between control and $\mathrm{PM}_{10}$-treated groups}

All mice increased in weight over the course of the experiment. There was a non-significant trend for the $\mathrm{PM}_{10}$-treated group (PM100 and PM200) to gain less weight (Figure 1A). AHR obtained by MCh challenge showed no significant changes among the three groups (Figure 1B). BALF cell counts were also not significantly different among groups (Figure 1C).
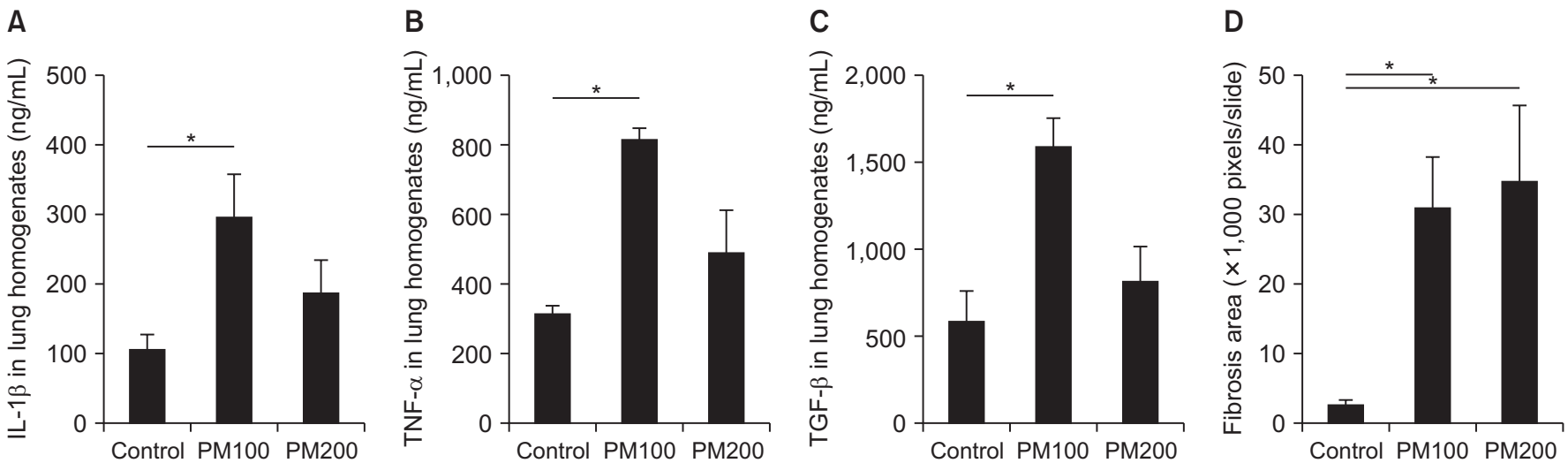

Figure 3. IL-1 $\beta$ (A), TNF- $\alpha$ (B), and TGF- $\beta$ (C) levels in lung homogenates were significantly higher in the PM100-treated group compared to the control group. Quantitative fibrosis was significant and severe in the $\mathrm{PM}_{10}$-treated group compared to the control group (D). IL-1 $\beta$ : interleukin 1 $\beta$; PM: particulate matter; TNF- $\alpha$ : tumor necrosis factor- $\alpha$; TGF- $\beta$ : transforming growth factor- $\beta$. ${ }^{*} \mathrm{p}<0.05$. 
A

\begin{tabular}{|c|c|c|c|}
\hline & $\begin{array}{c}\text { Fold change } \\
\left(\mathrm{PM}_{10} \text { vs. control) }\right.\end{array}$ & $\begin{array}{c}\text { Normalized data } \\
\left(\log _{2}\right) \\
\text { Control }\end{array}$ & $\begin{array}{c}\text { Normalized data } \\
\left(\log _{2}\right) \\
\mathrm{PM}_{10}\end{array}$ \\
\hline$R n 45 s$ & $8,058.365$ & 0.046 & 13.023 \\
\hline Snord22 & 675.879 & 0.046 & 9.446 \\
\hline Atp6v0c-ps2 & 194.596 & 0.048 & 7.653 \\
\hline Snora28 & 84.314 & 0.040 & 6.437 \\
\hline Snord15b & 78.076 & 0.039 & 6.326 \\
\hline Snora70 & 70.963 & 0.038 & 6.187 \\
\hline Mmp12 & 56.102 & 1.246 & 7.056 \\
\hline Rprl3 & 51.286 & 0.036 & 5.717 \\
\hline$B c 1$ & 42.404 & 0.034 & 5.440 \\
\hline Snora17 & 31.237 & 0.031 & 4.997 \\
\hline AA467197 & 27.239 & 0.818 & 5.586 \\
\hline Snora26 & 26.538 & 0.030 & 4.760 \\
\hline Ccl17 & 19.585 & 3.338 & 7.630 \\
\hline Rpph1 & 19.420 & 1.865 & 6.144 \\
\hline Clec4d & 18.464 & 1.815 & 6.021 \\
\hline$\approx \approx \approx \approx \approx \approx \approx \approx \approx \approx \approx \approx \approx$ & $E \approx \approx \approx \approx \approx \approx \approx \approx \approx \approx$ & $=\approx \approx \approx \approx \approx \approx \approx \approx \approx$ & $E \approx \approx \approx \approx \approx \approx \approx \approx \approx$ \\
\hline Lce3a & 0.004 & 8.049 & 0.000 \\
\hline Mylpf & 0.004 & 9.441 & 1.341 \\
\hline Tnnt3 & 0.003 & 9.394 & 1.204 \\
\hline Serpinb12 & 0.003 & 8.326 & 0.000 \\
\hline Crct1 & 0.003 & 8.528 & 0.000 \\
\hline Lgals7 & 0.003 & 8.740 & 0.182 \\
\hline Serpinb3c & 0.002 & 9.134 & 0.000 \\
\hline Mt4 (metallothionecin 4) & 0.002 & 9.233 & 0.000 \\
\hline Acta1 & 0.001 & 9.954 & 0.000 \\
\hline Tnnc2 & 0.001 & 9.988 & 0.000 \\
\hline Krt4 (keratin 4) & 0.001 & 10.232 & 0.226 \\
\hline Sprr2a3 & 0.001 & 10.174 & 0.000 \\
\hline Krtdap & 0.001 & 10.466 & 0.000 \\
\hline Krt13 (keratin 13) & 0.000 & 11.368 & 0.000 \\
\hline Chil4 (chitinase-like 4) & 0.000 & 11.664 & 0.091 \\
\hline
\end{tabular}

B

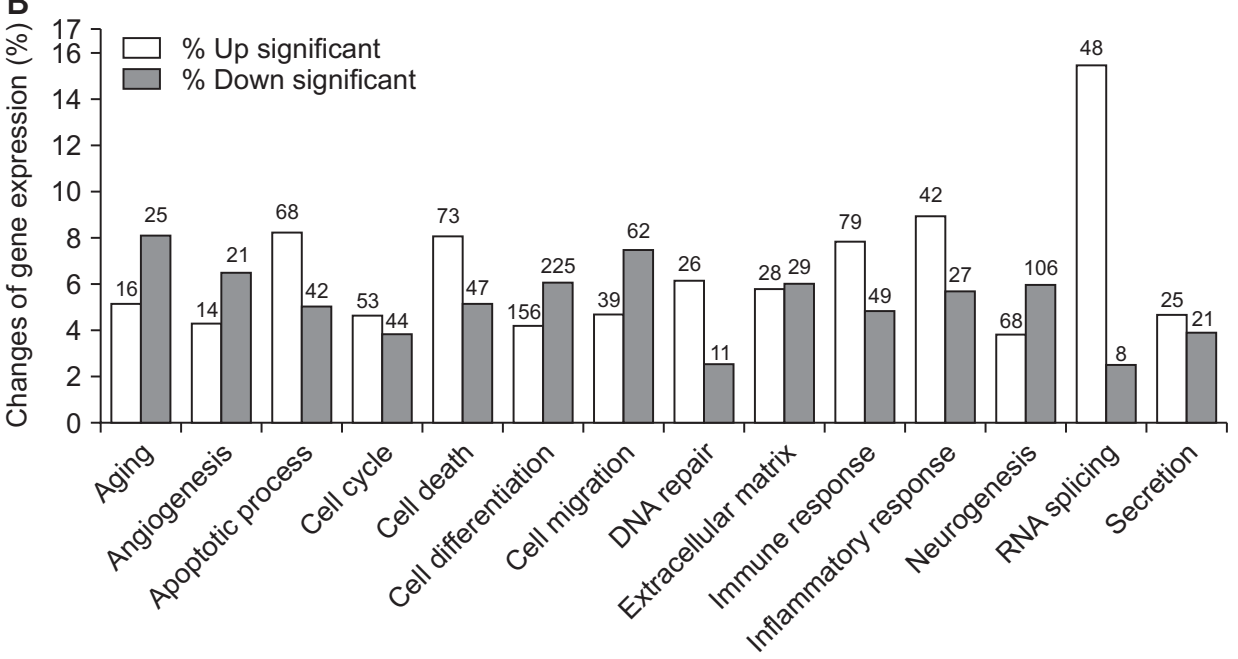

Figure 4. (A) Genes showing the largest difference between the control and $\mathrm{PM}_{10}$-treated groups. (B) RNA expression of genes associated with RNA splicing, DNA repair, the inflammatory response, the immune response, cell death, and apoptotic process were increased in the $\mathrm{PM}_{10}$-treated group compared to the control group. The number of genes with significant change are presented at the top of bar. PM: particulate matter. 


\section{Comparison of pathologic findings between control and $\mathrm{PM}_{10}$-treated groups}

Compared to the control group, the $\mathrm{PM}_{10}$-treated group (PM100 and PM200) showed cellular infiltration in the airway and lung parenchyme. Airway wall thickness, goblet cell hyperplasia, and inflammatory cellular proliferation were observed predominantly in the $\mathrm{PM}_{10}$-treated group. In addition, fibrosis in lung parenchyme and peribronchial tissues were also predominant in the $\mathrm{PM}_{10}$-treated group, compared to the control group (Figure 2).

\section{Comparison of cytokine levels in lung homogenates} and quantitative fibrosis between the control and $\mathbf{P M}_{10}$-treated groups

The levels of IL- $1 \beta$, TNF- $\alpha$, and TGF- $\beta$ in lung homogenates were higher in the $\mathrm{PM}_{10}$-treated group than in the control group, but statistical significance was observed only for the PM100 group (Figure 3A-C). As evidence by the results of the fibrosis-area analysis, $\mathrm{PM}_{10}$ induced significant lung fibrosis (Figure 3D).
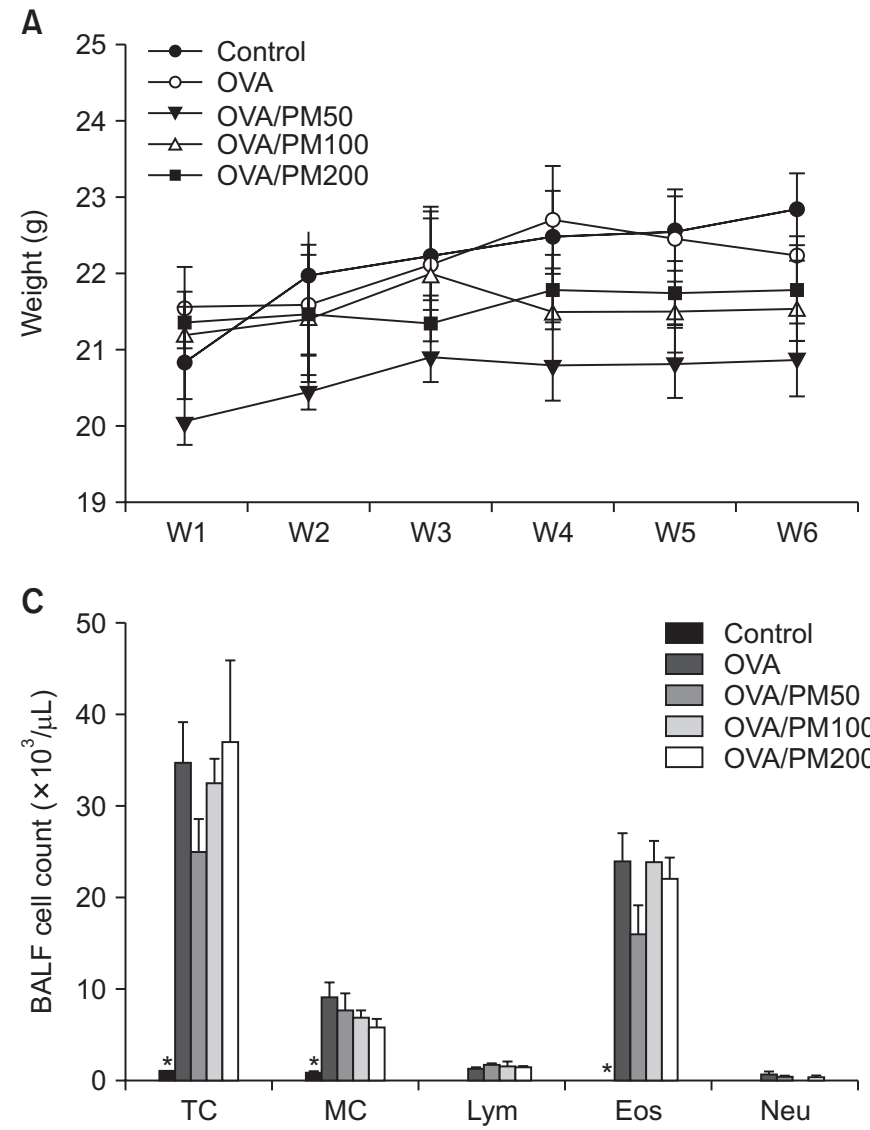

\section{Comparison of RNA expression between the control and $\mathrm{PM}_{10}$-treated groups}

The $\mathrm{PM}_{10}$ model showed increased RNA expression of Rn45a, Snord22 (small nucleolar RNA), Atp6v0c-ps2 (ATPase, $\mathrm{H}+$ transporting, lysosomal V0 subunit C, pseudogene 2), Snora28, Snord15b, Snora70, and Mmp12 compared to control group (Figure 4A). Generally, genes associated with RNA splicing, DNA repair, inflammatory response, immune response, cell death, and the apoptotic process were highly expressed in the $\mathrm{PM}_{10}$ model compared to control group (Figure 4B).

\section{Comparison of weight changes, airway hyper- responsiveness, and BALF cell count between the control, OVA, and OVA/ $/ \mathrm{PM}_{10}$-treated groups}

All mice increased in weight over the course of the experiment. Among all the groups, the final weight of the control group was the heaviest (Figure 5A). AHR obtained by MCh challenge in both OVA-treated groups (OVA and OVA/PM 10 ) was predominant compared to the control group. However, it was not significantly different between the OVA and OVA/ $\mathrm{PM}_{10}$-treated groups (Figure 5B). Total cell, macrophage, and

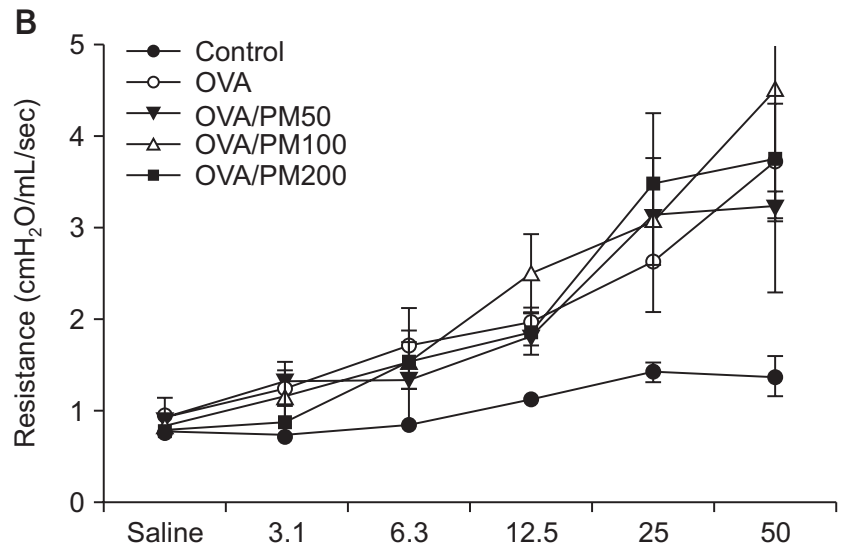

Figure 5. (A) Weight change was not significantly different among groups. (B) Airway hyper-responsiveness as determined by methacholine challenge were increased in the OVA and/or $\mathrm{PM}_{10}$-treated group. (C) BALF cell counts revealed significantly increased total macrophage and eosinophil counts in the both OVA and OVA/ $\mathrm{PM}_{10}$-treated groups compared to the control group. BALF: bronchoalveolar lavage fluid; OVA: ovalbumin; PM: particulate matter; TC: total cell; MC: macrophage; Lym: lymphocyte; Eos: eosinophil; Neu: neutrophil. ${ }^{*} \mathrm{p}<0.05$ between it and others. 
eosinophil counts in BALF were highly elevated in all OVAtreated groups compared with the control group. However, they were not significantly different between the OVA and OVA/ $\mathrm{PM}_{10}$-treated groups (Figure 5C).

\section{Comparison of pathologic findings between control, $\mathrm{OVA}$, and $\mathrm{OVA} / \mathrm{PM}_{10}$-treated group}

All OVA-treated groups showed prominent inflammatory cell proliferation and fibrosis in airway, peribronchial tissue, and lung parenchyme, compared to control group. However, treatment of OVA $/ \mathrm{PM}_{10}$ did not have additive effect on OVA alone (Figure 6).

\section{Comparison of cytokine levels in lung homogenates and quantitative fibrosis between in control, OVA, and $\mathrm{OVA} / \mathrm{PM}_{10}$-treated group}

The levels of IL-1 $\beta$, TNF- $\alpha$, IL-13, and TGF- $\beta$ in lung homogenates were increased in the OVA-treated group. However, the effects of OVA $/ \mathrm{PM}_{10}$ treatment were not greater than those of OVA alone (Figure 7A-D). Both OVA and OVA/PM 10 treatment induced significant lung fibrosis as evident in fibrosisare analysis; however, $\mathrm{OVA} / \mathrm{PM}_{10}$ treatment were not greater than those of OVA alone (Figure 7E).

\section{Comparison of RNA expression between the control and $\mathrm{OVA} / \mathrm{PM}_{10}$-treated groups}

The OVA/ $\mathrm{PM}_{10}$-treated model showed increased RNA expression of Clcal (chloride channel accessory 1), Snord22, Retnla (resistin like alpha), Prg2 (proteoglycan 2, bone marrow), Tff2 (trefoil factor 2), Atp6v0c-ps2, and Fcgbp (Fc fragment of IgG binding protein) compared to the control (Figure 8A). Overall, this model showed increased RNA expression of genes associated with RNA splicing, DNA repair, inflammatory response, and immune response compared to control group (Figure 8B).

\section{Discussion}

This study confirmed that $\mathrm{PM}_{10}$ can alter immune and inflammatory processes of the lung at the gene, protein, and cellular levels, using a murine model. In a substantial advance on previous work, we showed that exposure to $\mathrm{PM}_{10}$ can extensively alter RNA expression in lung homogenates. $\mathrm{PM}_{10}$ induced increased RNA expression associated with RNA splicing, DNA repair, cell death, apoptotic processes, the inflammatory response, and the immune response. The above processes are associated with the cell cycle, cell viability, and cellular proliferation. Potential consequences of such widely altered RNA expression profiles include necrosis, malignancy, and other diseases. Referring to the results of our RNA expression analysis, we can potentially predict various clinical effects
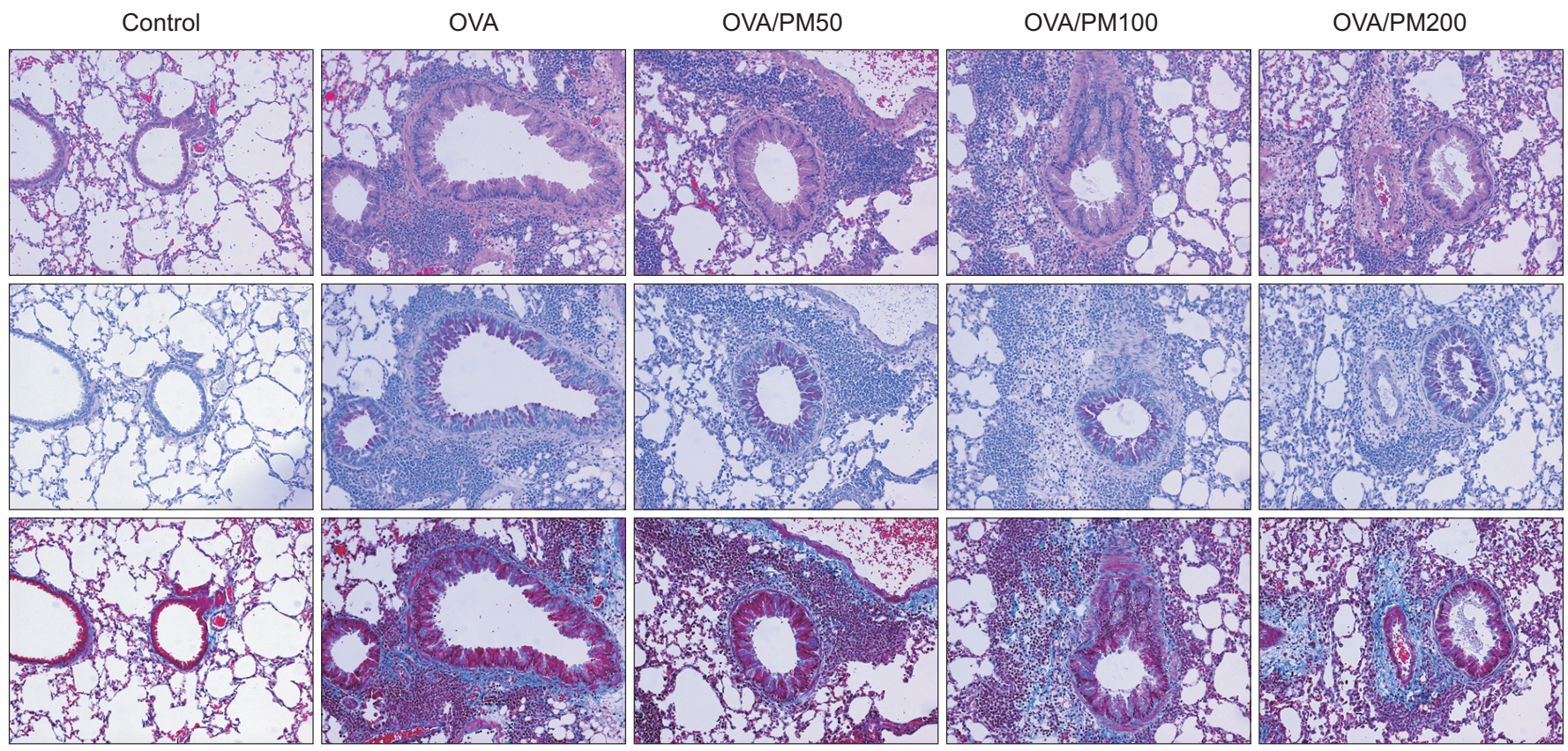

Figure 6. Pathological findings revealed that both the OVA and OVA $/ \mathrm{PM}_{10}$ treatments led to airway inflammation and lung fibrosis (H\&E, PAS, and M\&T; all ×200). H\&E: hematoxylin and eosin; OVA: ovalbumin; PAS: periodic acid-Schiff; PM: particulate matter; M\&T: Masson trichrome. 
A

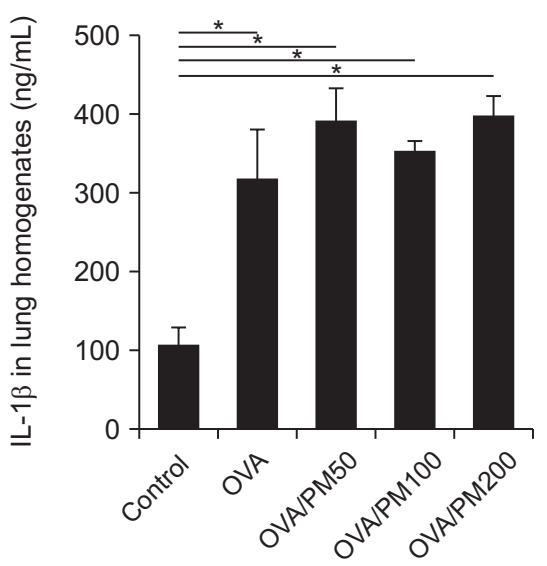

D

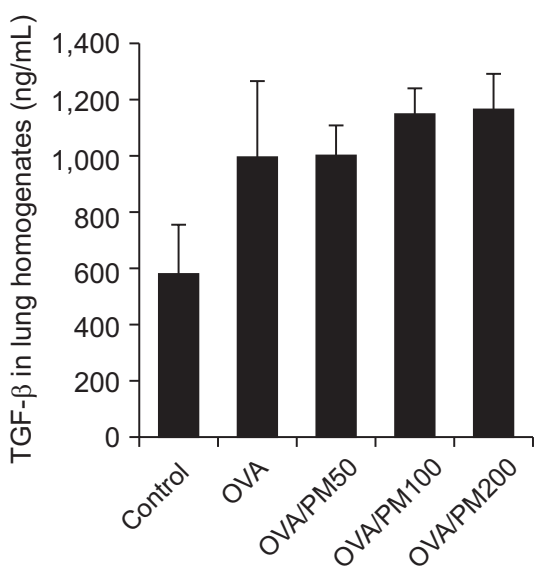

B

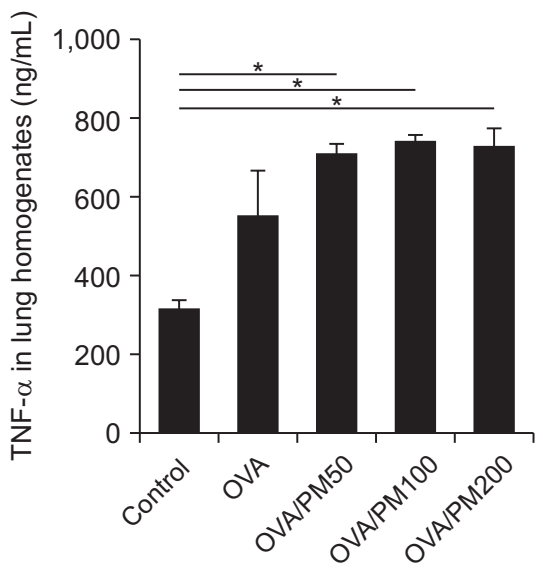

E

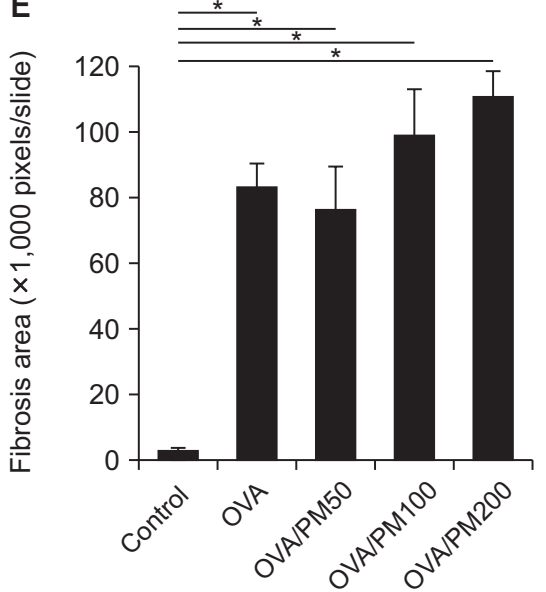

C

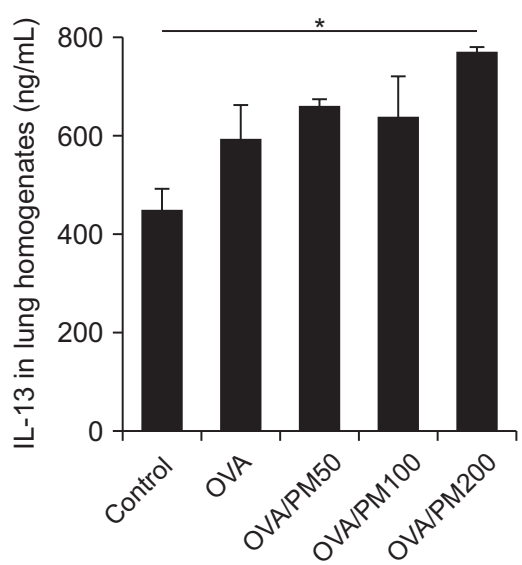

Figure 7. IL-1 $\beta$ (A), TNF- $\alpha$ (B), IL-13 (C), and TGF- $\beta$ (D) levels in lung homogenates were increased in the OVA and OVA/PM 10 -treated groups. Quantitative fibrosis was significant and severe in the OVA and OVA/PM 10 -treated groups compared to the control group (E). IL: interleukin; OVA: ovalbumin; PM: particulate matter; TNF- $\alpha$ : tumor necrosis factor- $\alpha$; TGF- $\beta$ : transforming growth factor- $\beta .{ }^{*} p<0.05$.

of $\mathrm{PM}_{10}$, and conduct further studies concerning mechanisms underlying these effects.

Inhalation of $\mathrm{PM}_{10}$ induced proliferation of inflammatory cells and fibrosis in peri-bronchial and lung tissue. We speculated that abundant helper T cell type I (Th1) type inflammatory cytokines increased in lung homogenates might lead to these changes. Some previous studies have shown similar results: Thl type inflammatory cytokines increased in $\mathrm{PM}_{10}$ treated mode ${ }^{24,25}$. Other studies also showed $\mathrm{PM}_{10}$ is associated with inflammation ${ }^{26}$ or fibrosis ${ }^{27}$ of lung. Based on this study and previous in vitro and in vivo studies, $\mathrm{PM}_{10}$ is definitely toxic material to airway and lung parenchyme. Many human studies also support that $\mathrm{PM}_{10}$ has negative effects on lung and airway diseases ${ }^{28}$.

It is notable that we observed extremely high expression of Rn45s (8,058-fold change), Snord22 (676-fold change), and Atp6v0c-ps2 (196-fold change) in the $\mathrm{PM}_{10}$ treated group, compared to the control group. Rn $45 \mathrm{~s}$ is known to be asso- ciated with RNA toxicity, but its function has not been fully elucidated $^{29}$. Snord22 is small nucleolar RNA. Atp6v0c-ps2 is associated with ATPase, $\mathrm{H}+$ transporting, and lysosomal V0 subunit C. This plays a central role in $\mathrm{H}(+)$ transport across cellular membranes ${ }^{30}$. In addition, Snora28, Snord15b, Snora70, Mmp12, Rprl3, BC1, Snora17, AA467197, Snora26, Ccl17, Rpph1, and Clec4d were also highly expressed in the $\mathrm{PM}_{10}$-treated group compared to the control group. These genes are associated with small nucleolar RNA, brain cytoplasmic RNA, or specific chemokines ${ }^{31,32}$. In the OVA $/ \mathrm{PM}_{10^{-}}$ treated group, the genes Clcal, Snord22, Retnla, Prg2, Tff2, Atp6v0c-ps2, Fcgbp, Muc5ac, Itln1, Ngp (neutrophilic granule protein), Fxyd4 (FXYD domain-containing ion transport regulator 4), Mzb1 (marginal zone B and B1 cell-specific protein 1), Mmpl2 (matric metallopeptidase 12), Camp (cathelicidin antimicrobial peptide), and TffI were upregulated compared to control group.

Some genes were extremely suppressed in the $\mathrm{PM}_{10}$-treated 
A

\begin{tabular}{|c|c|c|c|}
\hline & $\begin{array}{c}\text { Fold change } \\
\text { (OVA/PM } 10 \text { vs. control) }\end{array}$ & $\begin{array}{c}\text { Normalized data } \\
\left(\log _{2}\right) \\
\text { Control }\end{array}$ & $\begin{array}{c}\text { Normalized data } \\
\left(\log _{2}\right) \\
{\text { OVA } / P M_{10}}^{2}\end{array}$ \\
\hline Clca1 & $3,235.352$ & 12.464 & 0.804 \\
\hline Snord22 & 203.758 & 7.716 & 0.046 \\
\hline Retnla & 149.163 & 15.198 & 7.978 \\
\hline Prg2 & 91.784 & 7.591 & 1.071 \\
\hline Tff2 & 70.658 & 8.905 & 2.763 \\
\hline Atp6v0c-ps2 & 67.243 & 6.120 & 0.048 \\
\hline Fcgbp & 59.644 & 6.875 & 0.977 \\
\hline Muc5ac (mucine 5AC) & 58.342 & 5.978 & 0.111 \\
\hline ItIn1 (intelectin 1) & 49.599 & 5.974 & 0.342 \\
\hline Ngp & 45.142 & 7.168 & 1.671 \\
\hline Fxyd4 & 43.610 & 5.658 & 0.212 \\
\hline Mzb1 & 42.705 & 8.722 & 3.305 \\
\hline Mmp12 & 38.894 & 6.528 & 1.246 \\
\hline Camp & 37.851 & 6.829 & 1.587 \\
\hline Tff1 (trefoil factor 1) & 33.365 & 5.093 & 0.033 \\
\hline$\approx \approx \approx \approx \approx \approx \approx \approx \approx \approx \approx \approx \approx$ & $E \approx \approx \approx \approx \approx \approx \approx \approx \approx \approx$ & $\approx \approx \approx \approx \approx \approx \approx \approx \approx \approx$ & $E \approx \approx \approx \approx \approx \approx \approx \approx z$ \\
\hline Krt6b (keratin 6B) & 0.004 & 8.045 & 0.126 \\
\hline Serpinb12 & 0.004 & 8.326 & 0.376 \\
\hline Crct1 & 0.004 & 8.528 & 0.561 \\
\hline Mylpf & 0.004 & 9.441 & 1.463 \\
\hline$L c e 3 b$ & 0.004 & 7.997 & 0.006 \\
\hline Defb4 & 0.004 & 8.042 & 0.006 \\
\hline Lce3a & 0.004 & 8.049 & 0.006 \\
\hline Lgals7 & 0.003 & 8.740 & 0.395 \\
\hline Serpinb3c & 0.002 & 9.134 & 0.006 \\
\hline Mt4 (metallothionein 4) & 0.002 & 9.233 & 0.006 \\
\hline Krt4 (keratin 4) & 0.001 & 10.232 & 0.848 \\
\hline Acta1 & 0.001 & 9.954 & 0.194 \\
\hline Tnnc2 & 0.001 & 9.988 & 0.006 \\
\hline Krtdap & 0.001 & 10.466 & 0.006 \\
\hline Krt13 (keratin 13) & 0.000 & 11.368 & 0.153 \\
\hline
\end{tabular}

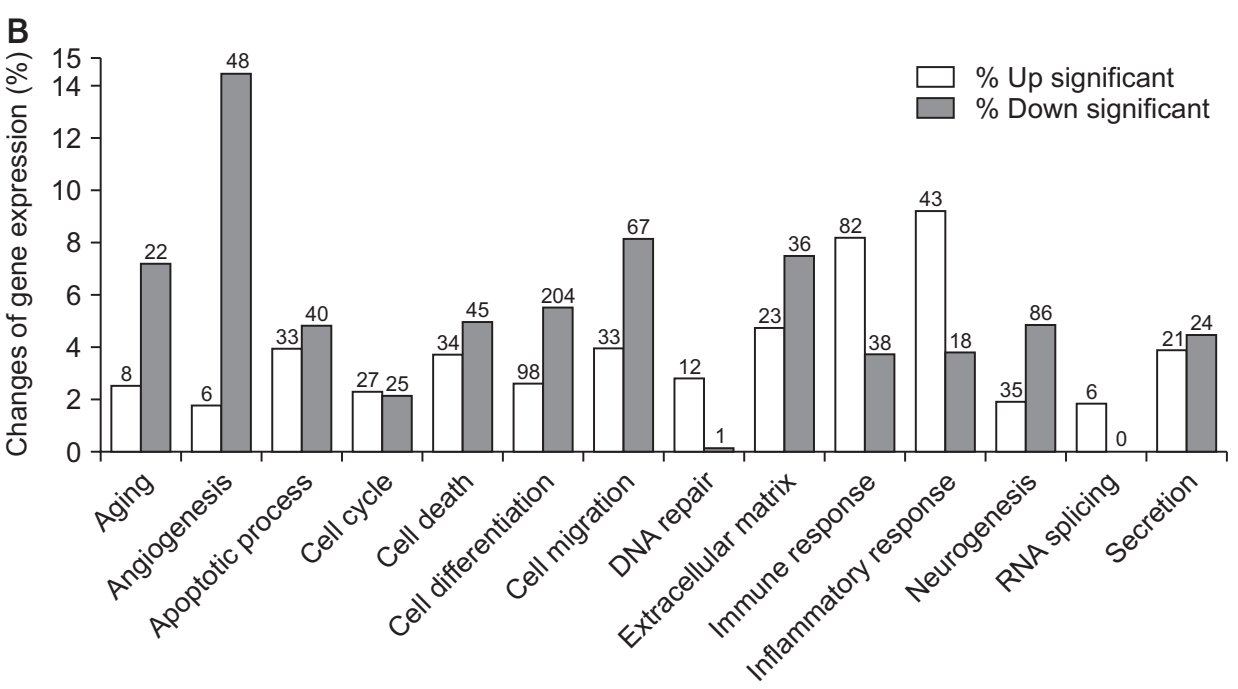

Figure 8. (A) Genes showing the largest difference between the control and OVA/ $\mathrm{PM}_{10}$-treated groups. (B) RNA expression of genes associated with RNA splicing, DNA repair, the inflammatory response, and the immune response were increased in the $\mathrm{PM}_{10}$-treated group compared to the control group. The number of genes with significant change are presented at the top of bar. OVA: ovalbumin; PM: particulate matter. 
group, compared to the control group: Chil4, Krt13, Krtdap (keratinocyte differentiation associated protein), Sprr2a3 (small proline-rich protein 2A3), Krt4, Tnnc2 (troponin C2, fast), Actal (actin, alpha 1, skeletal muscle), Mt4, Serpinb3c (serine peptidase inhibitor, clade B, member 3C), Lgals7 (lectin, galactose binding, soluble 7), Crctl (cysteine-rich C-terminal 1), Serpinb12 (serine peptidase inhibitor, clade B, member 12), Tnnt3 (troponin T3, skeletal, fast), Mylpf (myosin light chain, phosphorylatable, fast skeletal muscle), and Lce3a (late cornified envelope $3 \mathrm{~A}$ ). In the $\mathrm{OVA} / \mathrm{PM}_{10}$-treated group, the genes Krt6b, serpinb12, Crct1, Mylpf, Lce3b (late cornified envelope 3B), Defb4 (defensin beta 4), Lce3a, Lgals7, Serpinb3c, Mt4, Krt4, Acta1, Tnnc2, Krtdap, and Krt13 were substantially downregulated compared to the control group.

$\mathrm{PM}_{10}$ altered RNA expression in extensive range. It also increased production of inflammatory cytokines. Inflammation and fibrosis were also induced. However, its effects were only slightly greater than those of OVA. We used an acute-OVA model with intraperitoneal OVA sensitization and intranasal OVA challenge. This model also showed extensive changes of RNA expression and abundant inflammation. Because of the magnitude of the changes caused by OVA, additional effects of $\mathrm{PM}_{10}$ were not well revealed. In clinics, severe asthma often leads to hide the clinical effects of other underlying disease, like stable COPD ${ }^{33}$. However, Gold et al. ${ }^{34}$ showed that PM mediates and augments allergic sensitization and cellular proliferation using a murine model, and Clifford et al. ${ }^{35}$ showed that $\mathrm{PM}_{10}$ exposure exacerbates various responses to respiratory viral infection, e.g., increased inflammation and impaired lung function. Then, we are not sure whether addictive or synergic effects of $\mathrm{PM}_{10}$ in mild or chronic asthma model ${ }^{36}$. In order to further clarify whether $\mathrm{PM}_{10}$ has additive or synergic effects on an allergy model, a further-modified OVA model which does not hide the effects of $\mathrm{PM}_{10}$, is needed.

$\mathrm{PM}_{10}$ is a major air pollutant, and thus ends up in the human respiratory system where it can facilitate and aggravate allergic sensitization and airway inflammation ${ }^{17,37}$. This also alters defense mechanisms, including innate immunity in the lungs ${ }^{38}$. Thus, respiratory diseases can be developed and aggravated by exposure to $\mathrm{PM}_{10}$. However, studies elucidating the effects of $\mathrm{PM}_{10}$ using murine models are rare, and changes of RNA expression induced by $\mathrm{PM}_{10}$ have not been well studied. This study used standardized $\mathrm{PM}_{10}$ in a murine model, and showed extensive RNA expression changes. Our results can be used to inform future work using $\mathrm{PM}_{10}$-treated murine models, including further investigation of mechanisms underlying the damaging effects of $\mathrm{PM}_{10}$ on the airway and lung. Finally, this study will be helpful to search for therapeutic agents in $\mathrm{PM}_{10}$-exposured human airway and lung diseases.

We showed that inhalation of $\mathrm{PM}_{10}$ changed RNA expression in extensive range in a murine model. $\mathrm{PM}_{10}$ also induced increased production of inflammatory cytokines, cellular proliferation, and fibrosis. In an acute-OVA model, additional effects of $\mathrm{PM}_{10}$ were not observed. Our findings suggest $\mathrm{PM}_{10}$ can affect various airway and lung diseases.

\section{Authors' Contributions}

Conceptualization: Park HJ. Methodology: Han H, Oh EY. Formal analysis: Park HJ, Lee JH, Park JW. Data curation: Park HJ, Lee JH, Park JW. Software: Park HJ, Lee JH, Park JW. Validation: Han H, Oh EY, Park HJ, Lee JH, Park JW. Investigation: Han H, Oh EY, Park HJ, Lee JH, Park JW. Writing - original draft preparation: Park HJ. Writing - review and editing: Park HJ. Approval of final manuscript: all authors.

\section{Conflicts of Interest}

No potential conflict of interest relevant to this article was reported.

\section{Funding}

This study was supported by a 2019-grant from The Korean Academy of Tuberculosis and Respiratory Diseases.

\section{Supplementary Material}

Supplementary material can be found in the journal homepage (http://www.e-trd.org).

Supplementary Figure S1. Animal model design protocol. IN: intranasal treatment; IP: intraperitoneal treatment; OVA: ovalbumin; PM: particulate matter.

Supplementary Figure S2. Fast QC data in control (A), $\mathrm{PM}_{10^{-}}$ treated (B), and OVA/PM $\mathrm{PM}_{10}$-treated group (C). OVA: ovalbumin; PM: particulate matter.

\section{References}

1. Dockery DW, Pope CA, Xu X, Spengler JD, Ware JH, Fay ME, et al. An association between air pollution and mortality in six U.S. cities. N Engl J Med 1993;329:1753-9.

2. McCreanor J, Cullinan P, Nieuwenhuijsen MJ, Stewart-Evans J, Malliarou E, Jarup L, et al. Respiratory effects of exposure to diesel traffic in persons with asthma. N Engl J Med 2007;357:2348-58.

3. Kyung SY, Jeong SH. Particulate-matter related respiratory diseases. Tuberc Respir Dis 2020;83:116-21.

4. Yamada E, Funoki S, Abe Y, Umemura S, Yamaguchi D, Fuse Y. Size distribution and characteristics of chemical components in ambient particulate matter. Anal Sci 2005;21:89-94. 
5. Kumar RK, Shadie AM, Bucknall MP, Rutlidge H, Garthwaite L, Herbert C, et al. Differential injurious effects of ambient and traffic-derived particulate matter on airway epithelial cells. Respirology 2015;20:73-9.

6. Penard-Morand C, Raherison C, Charpin D, Kopferschmitt C, Lavaud F, Caillaud D, et al. Long-term exposure to closeproximity air pollution and asthma and allergies in urban children. Eur Respir J 2010;36:33-40.

7. Jacquemin B, Kauffmann F, Pin I, Le Moual N, Bousquet J, Gormand F, et al. Air pollution and asthma control in the epidemiological study on the Genetics and Environment of Asthma. J Epidemiol Community Health 2012;66:796-802.

8. Weinmayr G, Romeo E, De Sario M, Weiland SK, Forastiere F. Short-term effects of PM10 and NO2 on respiratory health among children with asthma or asthma-like symptoms: a systematic review and meta-analysis. Environ Health Perspect 2010;118:449-57.

9. Lee YM, Lee JH, Kim HC, Ha E. Effects of PM10 on mortality in pure COPD and asthma-COPD overlap: difference in exposure duration, gender, and smoking status. Sci Rep 2020;10:2402.

10. Wunnapuk K, Pothirat C, Manokeaw S, Phetsuk N, Chaiwong W, Phuackchantuck R, et al. PM10-related DNA damage, cytokinetic defects, and cell death in COPD patients from Chiang Dao district, Chiang Mai, Thailand. Environ Sci Pollut Res Int 2019;26:25326-40.

11. Heinrich J, Schikowski T. COPD patients as vulnerable subpopulation for exposure to ambient air pollution. Curr Environ Health Rep 2018;5:70-6.

12. Park YB, Rhee CK, Yoon HK, Oh YM, Lim SY, Lee JH, et al. Revised (2018) COPD clinical practice guideline of the Korean Academy of Tuberculosis and Respiratory Disease: a summary. Tuberc Respir Dis 2018;81:261-73.

13. Hirota JA, Gold MJ, Hiebert PR, Parkinson LG, Wee T, Smith $\mathrm{D}$, et al. The nucleotide-binding domain, leucine-rich repeat protein 3 inflammasome/IL-1 receptor I axis mediates innate, but not adaptive, immune responses after exposure to particulate matter under $10 \mu \mathrm{m}$. Am J Respir Cell Mol Biol 2015;52:96-105.

14. Wark PA, Johnston SL, Bucchieri F, Powell R, Puddicombe S, Laza-Stanca V, et al. Asthmatic bronchial epithelial cells have a deficient innate immune response to infection with rhinovirus. J Exp Med 2005;201:937-47.

15. Kicic A, Sutanto EN, Stevens PT, Knight DA, Stick SM. Intrinsic biochemical and functional differences in bronchial epithelial cells of children with asthma. Am J Respir Crit Care Med 2006;174:1110-8.

16. Zosky GR, Boylen CE, Wong RS, Smirk MN, Gutiérrez L, Woodward RC, et al. Variability and consistency in lung inflammatory responses to particles with a geogenic origin. Respirology 2014;19:58-66.

17. Hirota JA, Hirota SA, Warner SM, Stefanowicz D, Shaheen F, Beck PL, et al. The airway epithelium nucleotide-binding domain and leucine-rich repeat protein 3 inflammasome is activated by urban particulate matter. J Allergy Clin Immunol 2012;129:1116-25.

18. Reibman J, Hsu Y, Chen LC, Bleck B, Gordon T. Airway epithelial cells release MIP-3 $\alpha /$ CCL20 in response to cytokines and ambient particulate matter. Am J Respir Cell Mol Biol 2003;28:648-54.

19. Lee JH, Sohn JH, Ryu SY, Hong CS, Moon KD, Park JW. A novel human anti-VCAM-1 monoclonal antibody ameliorates airway inflammation and remodelling. J Cell Mol Med 2013;17:1271-81.

20. An TJ, Rhee CK, Kim JH, Lee YR, Chon JY, Park CK, et al. Effects of macrolide and corticosteroid in neutrophilic asthma mouse model. Tuberc Respir Dis 2018;81:80-7.

21. Kang JY, Kim IK, Hur J, Kim SC, Lee SY, Kwon SS, et al. Expression of muscarinic receptors and the effect of tiotropium bromide in aged mouse model of chronic asthma. Tuberc Respir Dis 2019;82:71-80.

22. Trapnell C, Pachter L, Salzberg SL. TopHat: discovering splice junctions with RNA-Seq. Bioinformatics 2009;25:1105-11.

23. Roberts A, Trapnell C, Donaghey J, Rinn JL, Pachter L. Improving RNA-Seq expression estimates by correcting for fragment bias. Genome Biol 2011;12:R22.

24. Huang KL, Liu SY, Chou CC, Lee YH, Cheng TJ. The effect of size-segregated ambient particulate matter on Th1/Th2-like immune responses in mice. PLoS One 2017;12:e0173158.

25. Miyata R, van Eeden SF. The innate and adaptive immune response induced by alveolar macrophages exposed to ambient particulate matter. Toxicol Appl Pharmacol 2011;257:20926.

26. Zosky GR, Iosifidis T, Perks K, Ditcham WG, Devadason SG, Siah WS, et al. The concentration of iron in real-world geogenic $\operatorname{PM}(1)(0)$ is associated with increased inflammation and deficits in lung function in mice. PLoS One 2014;9:e90609.

27. Zhao S, Wang J, Xie Q, Luo L, Zhu Z, Liu Y, et al. Elucidating mechanisms of long-term gasoline vehicle exhaust exposureinduced erectile dysfunction in a rat model. J Sex Med 2019;16:155-67.

28. Kwon SO, Hong SH, Han YJ, Bak SH, Kim J, Lee MK, et al. Long-term exposure to PM10 and NO2 in relation to lung function and imaging phenotypes in a COPD cohort. Respir Res 2020;21:247.

29. Rue L, Banez-Coronel M, Creus-Muncunill J, Giralt A, AlcalaVida R, Mentxaka G, et al. Targeting CAG repeat RNAs reduces Huntington's disease phenotype independently of huntingtin levels. J Clin Invest 2016;126:4319-30.

30. Kitagawa T, Taniuchi K, Tsuboi M, Sakaguchi M, Kohsaki T, Okabayashi T, et al. Circulating pancreatic cancer exosomal RNAs for detection of pancreatic cancer. Mol Oncol 2019;13:212-27.

31. Taye M, Lee W, Jeon S, Yoon J, Dessie T, Hanotte O, et al. Exploring evidence of positive selection signatures in cattle breeds selected for different traits. Mamm Genome 
2017;28:528-41.

32. Cai SR, Chen CQ, Wang Z, He YL, Cui J, Wu WH, et al. Expression of phosphatase of regenerating liver-3 in gastric cancer, its relationship with prognosis, and its role in gastric cancer cell proliferation. Zhonghua Yi Xue Za Zhi 2008;88:2326-30.

33. Park J, Kim EK, Kim MA, Kim TH, Chang JH, Ryu YJ, et al. Increased risk of exacerbation in asthma predominant asthmachronic obstructive pulmonary disease overlap syndrome. Tuberc Respir Dis 2018;81:289-98.

34. Gold MJ, Hiebert PR, Park HY, Stefanowicz D, Le A, Starkey MR, et al. Mucosal production of uric acid by airway epithelial cells contributes to particulate matter-induced allergic sensitization. Mucosal Immunol 2016;9:809-20.

35. Clifford HD, Perks KL, Zosky GR. Geogenic PM(1)(0) exposure exacerbates responses to influenza infection. Sci Total Environ 2015;533:275-82.

36. Cho YS, Oh YM. Dilemma of asthma treatment in mild patients. Tuberc Respir Dis 2019;82:190-3.

37. Heyder J. Deposition of inhaled particles in the human respiratory tract and consequences for regional targeting in respiratory drug delivery. Proc Am Thorac Soc 2004;1:315-20.

38. Parker D, Prince A. Innate immunity in the respiratory epithelium. Am J Respir Cell Mol Biol 2011;45:189-201. 